mortality seldom occur on a single plot. On hardwood rangelands, climatic variations from year to year or unusual events (e.g., fire, spring rain, low wildlife or livestock numbers) may cause a large group of acorns to establish at one time under favorable conditions. Other "unusual" events may be required for this pulse of seedlings to be recruited into the sapling and treesizeclasses. A short-term analysis of the distribution of tree sizes would not show any long-term pulses as they graduate from one size class to the next.

Despite this study's short time-frame, however, the relatively small number of saplings in the 5-to-10-foot class suggests that there may not be enough new oaks coming along to replace mature trees as they die. Field studies have been initiated by UC researchers to look for the source of pressure keeping oak seedlings from developing into saplings, whether it comes from climatic forces, wildlife-related damage, livestock damage, or insect pests.

This study does show that thereare fewer seedling and sapling oak than mature trees at the low rainfall zones of hardwood rangelands. These low elevations have the greatestmoisturelimitations, solandowners and resource managers need to be careful to maintain the health and vigor of the overstory trees. Recruitment of replacement trees may be very difficult to ensure, and may occur only in rare cases when acorn crop, grass competition, grazing pressure, soil moisture levels, and temperature are all favorable. Tree harvesting should be avoided in these low-elevation fringe areas where the first open stands of blue oak occur. At higher elevations, we found ample oak seedling regeneration to replace the mature trees in the stand. Still, we need to identify management practices landowners can use to ensure that seedlings can grow to the sapling and pole sizes, and eventually replace mature trees in the stand. Several studies now underway in different areas of California are evaluating a variety of management practices.

In future work, we will concentrate on developing models to evaluate the probability of adequate regeneration that will ensure the sustainability of oaks in hardwood rangeland areas. This will help landowners and policy makers concentrate their management activities such as firewood harvest or range improvement where regeneration. is less of a problem, and help them design mitigation practices to enhance regeneration success in difficult areas.

Richard Standiford is Forest Management Specialist, UC Berkeley; Neil McDougald is Cooperative Extension Farm Advisor, Madera County; Ralph Phillips is CE Farm Advisor, Kern County; and Aaron Nelson is CE Farm Advisor, Fresno County.

\title{
How quality relates to price in California fresh peaches
}

\author{
Douglas D. Parker $\square$ David Zilberman $\square$ Kirby Moulton
}

\section{During a single season, research- ers compared California fresh peaches for quality and price at the producer and retail levels. While prices at both levels declined dur- ing the season, they responded dif- ferently to changes in quality char- acteristics. The results suggest a potential for increased revenues from marketing sweeter, more ma- ture fruit.}

If fruit producers and marketers are to satisfy their customers, they must first understand consumer perceptions of fruit quality. Consumers base their choices on some combination of observable characteristics including fruitsize, color, shape, and amount of defects. These characteristics haveintrinsic value but also indicate nonobservable qualities such as sweetness, juiciness, texture, and flavor. Because what constitutes fruit quality is a subjective decision, produce purchased in the retail marketplace reflects the preferences of not only the consumer, but the grower, shipper, and distributor as well.

Some experts believe that fresh fruit producers have been slow in responding to increased consumer preferences for higher quality. Growers may not be aware of price signals, which represent consumer preferences for quality, because of the limitations of production and marketing systems. This article will explore the possibility that the price transmission mechanism is imperfect and could result in production inefficiencies. Correcting these inefficiencies could affect production decisions related to quality.

\section{Background}

Hedonic price analysis is a method developed by economists to estimate the value of different product characteristics. Users of this method assume that all consumers measure the level of different characteristics in a commodity the same way, but place unique values on those characteristics. These values are the hedonic prices of those characteristics.

The hedonic price literature dates back to an application of these ideas by Frederick Waugh in 1928. Waugh estimated hedonic pricesfor variouscharacteristics of vegetables on the Boston wholesale market. Hecollected data on prices and characteristics of asparagus, cucumbers, and tomatoes. The results of his analysis were a set of prices for characteristics. For example, Waugh found that by increasing the amount of greenness on the stalks of asparagus by one inch, the wholesale price increased by 34.45 cents per dozen bunches.

\section{Data collection and analysis}

This project involved the design, collection, and analysis of a large amount of data on quality characteristics of California fresh peaches. The quality characteristics measured were selected based on a review of relevant literature and consultation with industry and university researchers. Over 1,400 peaches were tested at the producer -level and over 1,000 peaches were tested at the retail level. The data collection period spanned 14 weeks, between mid-May and the end of August. The quality characteristics measured were background color (using industry-supplied color chips), redness, weight (fruit size), and soluble solids measured by sugar content which produces a sweet flavor.

Because a fruit's variety is known at the producer level, both buyers and sellers are able to roughly assess the level of maturity of the fruit from its background color. The background color variable at this level is therefore adjusted for varietal differences. Although producers may directly test for the level of soluble solids, consumers must deduce soluble solids from visual and aromatic characteristics, by shopping at specific stores with good reputations, or by returning to those stores which have been most satisfactory in the past.

Using computer regression techniques, we simultaneously analyzed the effects of quality characteristics and seasonal timing on both the producer and retail markets. For 


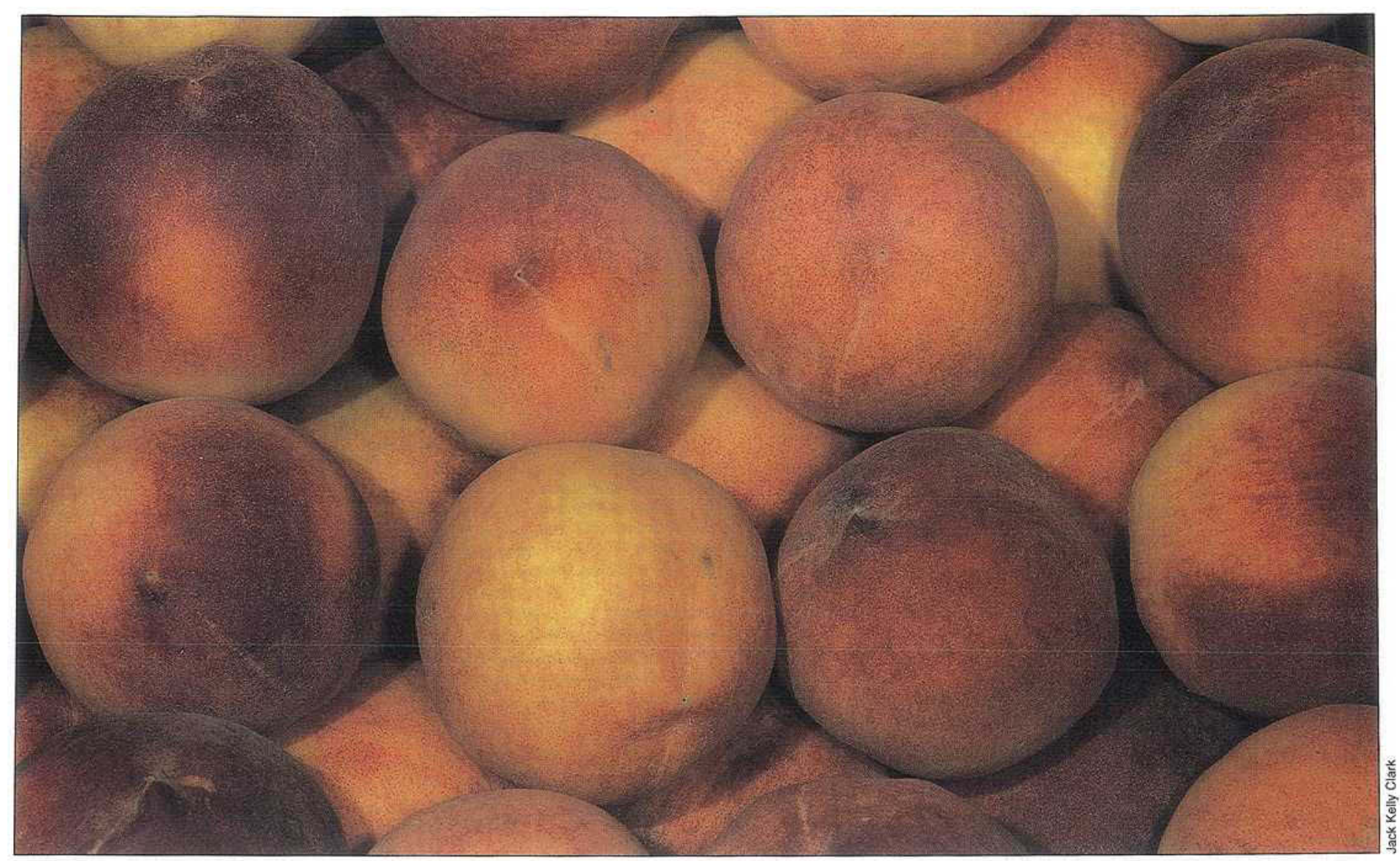

California fresh peaches.

the producer model, the characteristics that affected price were time during the season, backgrond color, and weight. At the retail level, the time during the season, weight, and level of soluble solids affected peach price.

The coefficients on redness are not statistically different from zero at either level of the marketing chain. Due to industry perceptions that redness is important, there is some concern with this result. The lack of statistical significance may be because the degree of variation in the redness variable is too small to measure adequately. Industry breeding programs have greatly decreased the variation in fruit redness over the years to the point where this may no longer be important to consumers.

Examples of the expected changes in price that would result from small changes in the variables at the producer and retail levels are presented in table 1. Because changes in this table are small, they are based on linear approximations of the graphs shown later. The price changes were less than $4 \%$ of the average producer level price, $\$ 8.78$ per lug, and the retail level price, $\$ 17.38$ per lug.

The results of our empirical regression analysis predict that the price per lug would drop 12.6 cents at the producer level and 17 cents at the retail level if the shipping date were delayed two days after July 10th. A 2-

\begin{tabular}{|c|c|c|c|c|c|}
\hline \multirow[t]{2}{*}{ Variable } & \multicolumn{2}{|c|}{ Average values } & \multirow{2}{*}{$\begin{array}{c}\text { Absolute } \\
\text { change }\end{array}$} & \multicolumn{2}{|c|}{ Price change per lug } \\
\hline & Producer & Retail & & Producer & Retail \\
\hline & & & & \multicolumn{2}{|c|}{ cents per lug } \\
\hline Shipping date & July 10,1988 & July 10,1988 & +2 days & -12.6 & -17.0 \\
\hline Days held & 3.5 days & NA & +0.5 days & -1.9 & NA \\
\hline Weight & 191 grams & 174 grams & +10 grams & +32.0 & +49.6 \\
\hline $\begin{array}{l}\text { Background } \\
\text { color }\end{array}$ & G-chip & J-chip & $+1 / 2$ unit & -2.2 & 0.0 \\
\hline Soluble solids & $11.4 \%$ sugar & $10.7 \%$ sugar & $+0.5 \%$ sugar & 0.0 & +15.2 \\
\hline
\end{tabular}

day delay in shipping date before July 10th would have a slightly greater effect, whereas a 2-day delay after July 10 th would have a smaller effect. These seasonal decreases in price assume that peach characteristics are held constant.

The average time between packing and shipping was found to be 3.5 days. The results predict that an increase in storage time of one-half day from this point would result in a loss of 1.9 cents per lug. This is in addition to any changes in price from a change in time of season (date). A similar measurement was not made at the retail level.

At both levels, changes in weight have the greatest impact on price. An increase of 10 grams per peach $(5.2 \%$ greater than the mean) will increase the producer price by 32 cents per lug. At the retail level, a weight increase of 10 grams ( $5.7 \%$ above the mean) increases the retail price by 49.6 cents per lug. For a given weight increase, there is a larger absolute price increase at the retail level than at the producer level.

Analysis of the background color variable revealed that color is only important at the producer level. Increases in background color by one-half unit (in California Tree Fruit Agreement (CTFA) Color Chips) caused producer prices to drop by 2.2 cents per lug 


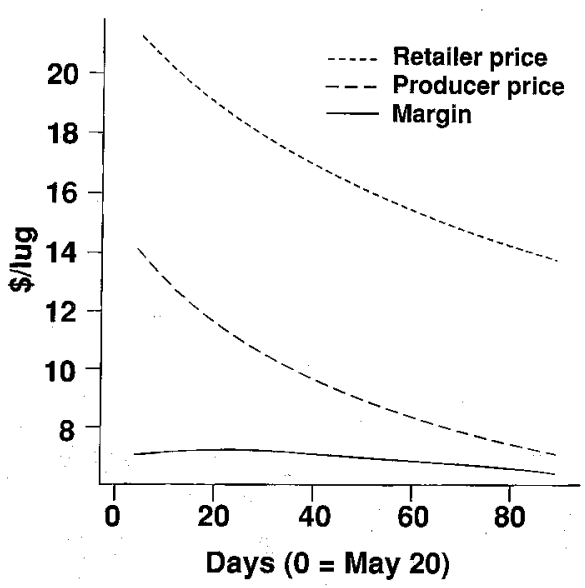

Fig. 1. Price and margin during the season.

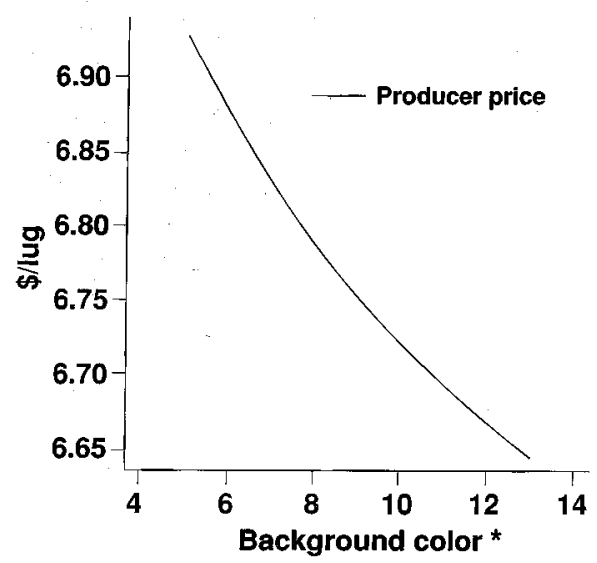

Fig. 3. Price by background color.

${ }^{*}$ CTFA color chips $\mathrm{E}-\mathrm{M}=5-13$.

with no affect on retail level prices. Producer prices may decrease with increased color because more color suggests less durability and greater losses in handling.

Soluble solids, measured here as \% Brix or percentage sugar by weight, had no significant impact on producer prices. However, at the retail level an increase of $0.5 \%$ Brix ( $4.7 \%$ above the mean) raised the retail price by 15.2 cents per lug.

The effects that these quality variables have on prices can also be seen graphically. Figure 1 shows predicted price behavior as the season progresses. Because retail prices decline more than producer prices, the marketing margin, depicted by the solid line, decreases during the season when other factors are held constant.

Weight has an importantimpacton prices and margins. It is, however, related to many other quality characteristics, such as soluble solids, maturity, and firmness. If all variables except weight are held at their average values, the effect of peach weight as a proxy for quality can be shown (see table 1). Predicted prices and margins are shown for average

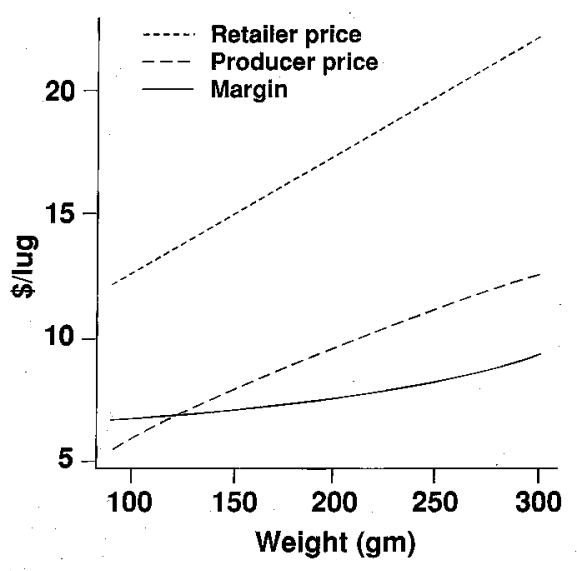

Fig. 2. Price and margin by weight.

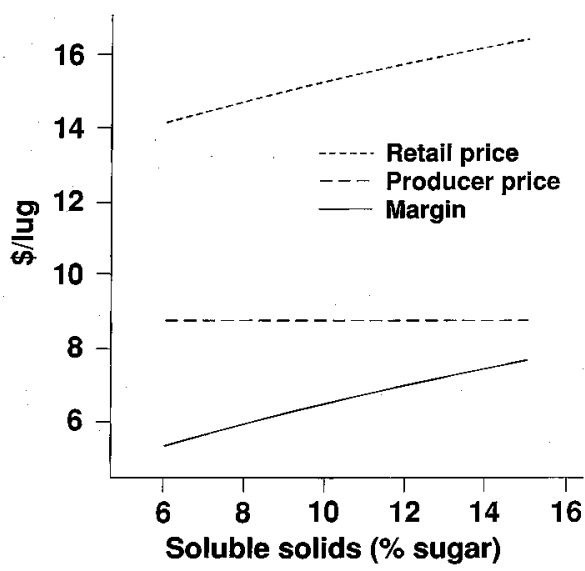

Fig. 4. Price and margin by soluble solids.

fruits, by weight, in figure 2 . The margin between producer and retail prices increases as weight increases.

The effect of background color on prices is depicted in figure 3 . The effect at the producer level appears greater than it actually is due to the price scale in this figure. The total variation in price over the entire range of background colors which was observed is only 35 cents. Background color had no effect on retail price.

Figure 4 shows the relationship between solublesolids and prices. The level of soluble solids was found to have no effect on price at the producer level. At the retail market, increased levels of soluble solids led to higher prices and marketing margins.

\section{Capitalizing on research results}

By recognizing which characteristics are important to the consumer, the industry can better serve the consumer. When we examine the characteristic weight, we see that benefits to producers from increased weight already exist. Given that the margin from increased weight becomes larger, further gains to the producer may be possible. This is dependant upon whether there are increased costs to wholesalers and retailers from handling larger fruit.

Weobserved that thelevel of background color affects price only at the producer level. At this level, the greener fruit receives greater prices. This is most likely an attempt to minimize levels of damage and decay that occur between the producer and retail levels. Therefore, given the current state of the ind ustry, there is little gain to be made from only altering the background color.

The most surprising result of this analysis is probably the effect of soluble solids (measured by sugar content) on prices. At the producer level soluble solids are unimportant in determining price, while at the retail level a higher level of soluble solids can increase price over $\$ 2$ per lug. It is possible that retailers sample the fruit to determinesolublesolids and set price accordingly. However, the evidence in thisstudy suggests that the industry may be losing potential revenues by not fully capitalizing on the consumer's preference for higher levels of sugar and other soluble solids. An analysis of marketing costs for mature fruit is needed to assess the profitability of increasing soluble solids.

Producers can gain from developing a price structure that compensates them for quality characteristics other than weight, in particular solublesolids. Our analysis shows that both producers and marketing firms receive a price premium for higher levels of weight, but that only marketing firms receive a price premium for other quality characteristics. Webelievemuch of this price premium is absorbed by losses in the distribution channel. If losses are reduced, this price premium could be distributed among producers and marketing firms. The premium at the producer level would stimulate an increase in production quality.

This study suggests a potential for increased revenue generated by marketing more mature fruit. A significant implication of this is that additional research is needed to develop (1) cost effective ways of handling mature fruit, and (2) varieties that are better suited for shipment in a mature state.

Douglas D. Parker is Assistant Professor, Center for Public Issues in Biotechnology, University of Maryland, College Park, and was a Post-Graduate Researcher, Department of Agricultural and Resource Economics, UC Berkeley, while this research was being performed; David Zilberman is Professor, Department of Agricultural and Resource Economics, UC Berkeley; and Kirby Moulton is Extension Economist, UC Berkeley.

The authors thank Lisa Schmidt for her assistance in data collection. This research was supported in part by the California Tree Fruit Agreement. 